\title{
REPRESENTAÇÕES DE ENERGIA QUE CIRCULAM NA MÍDIA E SUA NATUREZA NO CONTEXTO DA EDUCAÇÃO EM CIÊNCIAS
}

\author{
Carmen Irene Correia de Oliveira \\ Universidade Federal do Estado do Rio de Janeiro, \\ Rio de Janeiro, Brasil \\ Maria Auxiliadora Delgado Machado \\ Universidade Federal do Estado do Rio de Janeiro, \\ Rio de Janeiro, Brasil \\ Guaracira GouvÊA de SOUSA \\ Universidade Federal do Estado do Rio de Janeiro, \\ Rio de Janeiro, Brasil
}

\begin{abstract}
Resumo: Discutimos os diferentes modos de significação da palavra energia, presente nas discursividades de diferentes espaços de circulação dos sujeitos, comparando ao seu contexto de produção na física. Focalizamos o uso do termo energia em algumas propagandas de grande circulação na mídia. A partir de nossas argumentações entendemos que as representações de energia, construídas segundo o objetivo de propaganda, ao circularem na mídia constituem um conjunto de memórias que os sujeitos comuns compartilham por estarem expostos às mesmas mensagens midiáticas. $\mathrm{O}$ modo abstrato de pensar o conceito no campo científico defronta-se com perspectivas que se apoiam em associações cotidianas, exigindo um movimento de construção de conhecimento, que agrega à energia outros tantos conceitos abstratos.
\end{abstract}

Palavras-chave: Ensino de ciências. Significações de energia. Dispositivos midiáticos. Discursos. 
INTRODUÇÃO

Energia não é somente um conceito físico. Ela é uma representação do desenvolvimento tecnocientífico, do qual a modernidade foi o contexto, possibilitando pensar na tecnologia que permitiu das máquinas térmicas à bomba atômica, chegando, na contemporaneidade, à noção de energia como algo indispensável ao futuro da humanidade no planeta. Mas será que esse conceito, tendo em vista a educação/cultura científica, é algo apreensível em sua forma científica? Será que ele não entra no embate com representações que circulam no cotidiano e que permitem pensar em "diferentes energias"? Enfim, energia é o quê?

Este trabalho se insere no contexto de duas pesquisas interinstitucionais ${ }^{1}$ que tem como um dos objetivos articular investigações que exploram como o conceito de energia vem sendo representado nas questões do ENEM. Nas discussões empreendidas no bojo dessas investigações, surgiram interrogações acerca dos modos de significação da palavra energia, pois diferentes discursividades parecem indicar um distanciamento em relação à noção científica do termo, quando se considera os diferentes espaços de circulação dos sujeitos.

Das interrogações às suposições, colocamos a mídia no centro do debate e os produtos midiáticos como veículos de representações compartilhadas, chegando à influência da propaganda no cotidiano. Entendemos, nesse sentido, que tais representações vão refletir na formação cultural, no sentido lato, e no espaço escolar, de modo estrito, e, consequentemente, impactar o ensino. De modo mais específico, apresentamos uma análise de propagandas de produtos que usam o termo energia para subsidiar uma compreensão sobre como a relação entre duas concepções (aquela oriunda de um campo científico e aquela que circula no cotidiano) podem originar determinadas noções sobre o que é e como se comporta a energia. A propaganda emerge nesse circuito por conta de sua circulação midiática e por entendermos que, como produto cultural, ela trabalha com representações em um duplo movimento: tanto as cria como as consolida, caso elas se originem de outros espaços. Nesse sentido, a partir de questões como memória comum e representações, discutimos alguns sentidos de energia presentes em propagandas que circulam no cotidiano, e entendemos que tais modos de representação consolidam imagens que são levadas para o espaço da escola. 
O nosso corpus foi construído a partir de um procedimento exploratório na internet e abarca imagens e vídeos com o termo energia. Em um primeiro passo, a partir das várias possibilidades, delimitamos um conjunto de propagandas de gênero alimentício e outro de agências de energia brasileiras. Em um segundo passo, elegemos as propagandas que consideramos mais representativas: aquelas do produto Nescau e as peças comemorativas dos 50 anos da Eletrobrás, de 2012 nas quais o termo energia é recorrente. O objetivo de explorar as propagandas que têm o termo energia como ponto central apoia-se no pressuposto de que os produtos midiáticos se apresentam em um amplo circuito de produção e circulação, significando a diferentes públicos com vistas ao desenvolvimento de uma necessidade de consumo. Desse modo, entendemos que a discussão sobre os sentidos produzidos em torno do termo energia não pode descuidar do contexto maior da sociedade do consumo, onde o conceito em foco é apropriado no seu sentido não científico, contribuindo para fundamentar outro nível de compreensão que é levado ao espaço da educação escolar. Isso significa afirmar que as propagandas, como objetos problematizados, circulam na sociedade do consumo e têm relação com a cultura de massa. Os sujeitos constroem representações e as carregam para diferentes lócus de socialização e os momentos e espaços de educação formalizada não escapam a essa dinâmica.

A propaganda tem estreita relação com a questão da representação. Isso não é diferente no campo da educação e ela se difunde por meio de diversas mídias. Estudos no campo da educação que tomam como objeto a mídia e discutem sua centralidade na contemporaneidade e os processos educativos das crianças e dos jovens e seus processos de subjetivação, nesse contexto, há aqueles que têm como objeto a propaganda, dando ênfase à questão do consumo. Há, também, pesquisas que exploram o potencial de a peça de publicidade funcionar como texto em práticas pedagógicas e como veículo para uma formação crítica face ao social. Na educação, na interface entre educação e comunicação cabe destaque aos trabalhos de Belloni (2008; 2009), Pereira (2009; 2013), Fischer (2011; 2012) e Duarte (2008; 2013).

No início desta introdução, afirmamos que energia não é somente um conceito físico. Mantemos a posição, mas destacamos sua conceituação na área de Física e os modos de significação que impregnam a representação dos jovens que são o público do ensino de ciências e constituem nosso foco de investigação. 


\section{A CULTURA E A CULTURA DE MASSA: ASPECTOS FUNDAMENTAIS}

A abordagem do sentido de cultura presente em nossos trabalhos toma como base diferentes autores, tendo como ponto de partida aqueles que discutem tal conceito no campo da Antropologia. Para esses autores, a herança cultural funciona como um condicionante dos modos de ação do homem e dos grupos por ele formado, sendo, nesse sentido, fruto de uma operação de determinada cultura. Tal condição levou a uma ordem de valores nos quais determinados padrões culturais eram aceitos e outros eram depreciados. "O modo de ver o mundo, as apreciações de ordem moral e valorativa, os diferentes comportamentos sociais e mesmo as posturas corporais são assim produtos de uma herança cultural, ou seja, o resultado da operação de uma determinada cultura"(LARAIA, 1996, p. 70). Em Claval (1999), podemos depreender que o entendimento de cultura passa por noções como representações coletivas e organização de mundo. A cultura faz passar (como herança) de uns aos outros as representações coletivas, e, com isso, o que lemos e compreendemos na sociedade é o que aprendemos a ver em decorrência dessa herança cultural. Claval (1999), a partir de vários autores, afirma que "A apreensão do real reveste-se sempre de uma dimensão social: as representações que vêm da coletividade ajudam os homens a estruturar e pensar seu meio e a lhe dar um sentido, mas os impedem, frequentemente, de ver alguns de seus traços" (1999, p. 81). A organização do mundo é decorrência desse processo de herança relacionada às representações, pois estas estariam fundamentando os conceitos, as teorias e as concepções que estão na base do saber. "Cada cultura caracteriza-se por um sistema original de representações e de construções intelectuais. Isto não ocorre sem influência sobre a afetividade e sobre a atividade" (CLAVAL, 1999, p. 81). Assim, a cultura está associada ao mundo simbólico construído pelos sentidos que damos a nossas formas de viver, e em nossas práticas sociais produzimos cultura que em "seu sentido vasto remete aos modos de vida e de pensamento" (CUCHE, 2002, p.11). Desse modo, abordamos tanto a materialidade de objetos utilizados em nossos modos de vida, bem como na imaterialidade dos valores simbólicos constitutivos desses modos de vida e dos pensamentos.

Do campo dos estudos culturais, temos uma discussão mais abrangente. Williams (2000) parte de uma acepção na qual cultura designa um processo de desenvolvimento intelectual, espiritual e estético, ou um modo particular de vida, quer seja de um povo, um período, um grupo ou da humanidade em geral. Mas, também é preciso perceber que essa 
noção também descreve as obras e as práticas da atividade intelectual e, particularmente, artística. Tendo como referência o uso contemporâneo do termo, Williams indica que é esse o sentido mais difundido: "[...] cultura é música, literatura, pintura, escultura, teatro e cinema. Um Ministério da Cultura refere-se a essas atividades específicas, algumas vezes com o acréscimo da filosofia, do saber acadêmico, da história [...]" (2000, p. 121). Nesse autor, encontramos uma distinção significativa tendo em vista os nossos estudos. Williams afirma que, se na arqueologia e na antropologia cultural, o uso desse termo aponta para a produção material, no campo da história e nos estudos culturais, por outro lado, cultura parece significar, fundamentalmente, um sistema de significação ou um sistema simbólico.

A aproximação da ideia de cultura de um processo formador em termos sociais e históricos traz, para nossas questões, uma perspectiva que deve ter um lastro nas discussões que tomam a cultura de massa, primordialmente. Assim, ter como pressuposto de que há formas pelas quais "[...] uma dada ordem social é comunicada, reproduzida, vivenciada e estudada [...]" (WILLIAMS, 2000, p. 12-13), permite que focalizemos nosso objeto no contexto de uma sociedade do consumo, onde produtos como as propagandas constroem significâncias que circulam e são compartilhadas, constituindo não somente sujeitos desejantes (dos produtos propagandeados), mas, também, novas formas de compreender determinadas noções.

No que diz respeito às propagandas, elas funcionam para difundir determinadas representações, e por vezes sedimentá-las, no espaço do senso comum. Desse modo, é possível entendê-las como veículos argumentativos que atingem um determinado público, com estratégias persuasivas veiculando os produtos consumíveis que procuram vender. Indo além da comercialização desses produtos, procuramos entender como os slogans e as imagens funcionam na condição de sedimentar determinadas representações de energia que fundamentam um sentido que será levado ao espaço escolar, que constitui o lócus de aprendizado científico em primeira instância. Os conceitos nele trabalhados constituem tradução das teorias científicas e os diferentes materiais didáticos funcionam para propagar uma ideia específica que determinada área tem de suas concepções fundamentais.

Ao apresentar um panorama acerca das teorias da cultura do consumo, Feartherstone (1995) passeia por diferentes teóricos que discutem, sob a perspectiva materialista, a expansão da produção capitalista. Segundo o autor, afirma-se que tal expansão necessitou, para sua consolidação, da construção de novos mercados "e da educação de novos públicos 
consumidores por meio da publicidade e da mídia" (p. 32). Nesse processo, amplamente discutido por alguns teóricos da Escola de Frankfurt, temos a posição de Adorno para quem as mercadorias, que possuem um valor inicial de mercado, ficam livres para adquirirem um valor secundário, ou seja, "[...] as mercadorias ficam livres para adquirir uma ampla variedade de associações e ilusões culturais" (p. 33). A publicidade, nesse sentido, foi hábil em explorar essa possibilidade, "fixando imagens de romance, exotismo, desejo, beleza, realização, comunalidade, progresso científico e a vida boa nos bens de consumo mundanos, tais como sabões, máquinas de lavar, automóveis e bebidas alcoólicas" (p. 33).

Cabe salientar que há posicionamentos céticos com relação à capacidade de convencimento da publicidade em induzir o consumo e "doutrinar" consumidores (FEARTHERSTONE, 1995). No entanto, ao colocar nossas discussões no âmbito de um sistema que tem a cultura de consumo como pano de fundo, procuramos deslocar a compreensão sobre os modos de significação de conceitos científicos para o espaço de uma cultura que tem na circulação de imagens e mercadorias o seu forte.

Como em nossas investigações nos deparamos com sentidos de energia associados a diferentes ações que estão presentes no cotidiano, perguntamo-nos? Há justaposições entre os significados de energia que circulam em comerciais de determinados produtos e a conceituação científica? As qualidades associadas à energia, em tais publicidades, não acarretariam distorções na própria forma de significar energia a partir dos conteúdos de física?

Neste artigo, empreenderemos análises que conduziram não a respostas positivas ou negativas, mas a posicionamentos que serão confrontados com as práticas em ensino de ciências.

\section{ENERGIA COMO CONCEITO FÍSICO E O ENSINO DE CIÊNCIA}

Como nos diz Bauman (1998, p. 160), "à medida que se desenvolvem e amadurecem, os conceitos começam a se mover por conta própria e, às vezes, alcançam territórios bastante distantes de seu local de origem". Assim, para discutir energia (conceitual), passaremos por sua área de origem e chegar às suas formas de representação. De imediato, é necessário retornarmos à Revolução Industrial, contexto de produção ao qual o conceito de energia está associado, mesmo que no início não se apresentasse em sua forma "acabada". Nessa época, o conceito que circulava era o de força, cujo sentido guardava uma forte relação com a chamada força viva ou vis 
viva em latim. (VALADARES, 2000). Mesmo nos trabalhos de Joule, que deu importantes contribuições para a estruturação da termodinâmica, ${ }^{2}$ não há referência à energia e sim a uma forma de "força" que definiria a natureza do calor. A ideia de conservação dessa "força" estava bem fundamentada nesse período. Mesmo a primeira Lei da Termodinâmica, popularizada como o princípio de conservação de energia, não fazia menção ao conceito de energia como formulado originalmente por Helmotz, em artigo publicado em 1847. Nesse documento, reconhecido pelo campo da física e da história da ciência, o autor ainda adotava o termo braft (força) que é uma grandeza cuja natureza não se altera e a tratava de forma a considerar a possibilidade de uma alteração, mas que se conservava em quantidade (AUTH e ANGOTTI, 2001, p.220).

Segundo Bucussi (2006), somente a partir da demonstração matemática da primeira Lei Termodinâmica, em 1865, por Rudolf Clausius, foi que energia recebeu significado preciso e passou a ser conceituada como uma "função de estado", 3 ou seja, uma característica que se refere apenas ao estado do sistema nos instantes inicial e final, cuja evolução é desprezada. Nesse sentido, o valor da energia como conceito reside em dois elementos: transformação e conservação (FRENCH apud PASSOS, 2009, p.3603).

Retornado à questão da força, com a qual energia guarda relação, durante séculos a força motriz (correntezas e os desníveis dos rios; animais de tração; força humana) era a única fonte de energia utilizada na geração de produtos para vida humana. A estruturação das bases teóricas da Termodinâmica ocorre de forma simultânea ao processo de industrialização e desenvolvimento, principalmente em alguns países da Europa. Esse contexto demandou uma busca por produtos naturais que se convertessem em fontes de calor, como a lenha dos bosques, o carvão e o petróleo em geral, longe dos centros de produção para as máquinas necessárias ao processo de industrialização. No entanto, essas máquinas, tinham baixo rendimento.

Com o advento da eletricidade, ao final do século XIX, há outra mudança: ocorreu o desenvolvimento de máquinas elétricas que possuíam um melhor rendimento em relação às máquinas térmicas. Além disso, a eletricidade podia ser gerada longe dos centros produtivos e distribuída. O processo de desenvolvimento foi acelerado e condicionando a produção de energia à eficiência do combustível utilizado. Essa ideia de eficiência vai excluindo a ação humana e animal da participação da forma de produção. De forma simultânea, o conceito de energia vai sendo trabalhado em 
outros campos da física e se popularizando na linguagem não científica. A eletricidade passa a desempenhar um papel fundamental no processo de mecanização, de forma que a tríade energia-eletricidade-desenvolvimento começa a se articular e a traçar um cenário que propicia com veemência, o lucro e a acumulação.

Durante o século $X X$, a articulação desses elementos se fortalece e é incorporada ao senso comum, contribuindo não somente para a consolidação de uma ideia de energia como algo concreto, mas também para sua valorização como um produto de mercado. $\mathrm{O}$ uso intensivo de energias demandava menos a presença humana, reforçando a ideia de que a produção de energia diminui o esforço necessário para realização de uma ação. Com o desenvolvimento técnico-científico cada vez maior, o conceito de energia como capacidade de realizar trabalho se fundamenta, sendo uma definição restrita à energia mecânica. Tal conceito passa a se confundir com a facilidade de realizar uma ação de forma eficiente e a significar algo que devemos pagar para poder realizar tarefas com mais conforto em menos tempo (FRENCH apud PASSOS, 2009).

Assim, ao final do século XIX, para muitos, a física está completa em sua estrutura teórica, cujas bases estão alicerçadas nos princípios de conservação da massa e da energia, que constituíam conceitos de natureza completamente distinta. Nos anos iniciais do século XX, o mundo microscópico começa a ser estudado, buscando, entre outras coisas, entender as questões ligadas à energia nas reações químicas. Os trabalhos de Max Plank mostram que a energia transportada na forma de radiação pode ser expressa de outra forma além da contínua associada à ideia de onda, mas também de forma quantizada, em pacotes de energia cuja massa de repouso é nula e se deslocam a velocidade da luz. ${ }^{4} \mathrm{~A}$ esse trabalho soma-se o corpo teórico da teoria da relatividade Geral de Einstein, que matematiza essa questão na famosa expressão $\mathrm{E}=\mathrm{mc}^{2}$, impondo dessa forma uma interrelação e mesmo uma interdependência entre essas duas quantidades, massa e energia, que passam, juntas, a descrever o mundo para além dos limites do mundo newtoniano que prevalecia até então e no qual elas eram manipuladas separadamente.

No campo da educação, o conceito de energia foi considerado tema transversal nos documentos oficiais brasileiros, ou seja, algo considerado importante não somente pelo conteúdo a ele relacionado, mas também pela facilidade que ele tem de circular entre as diferentes disciplinas de forma multi ou mesmo interdisciplinar. Alguns aspectos já chamam a 
atenção desde as séries iniciais. Podemos observar, por exemplo, em um trecho do Referencial Curricular Nacional para a Educação Infantil (BRASIL, 1998a) uma tentativa de introduzir a ideia de transformação na natureza com o conceito de energia relacionado. "Há uma grande variedade de objetos presentes no meio em que a criança está inserida, [...] que se transformam ao longo do tempo, que reagem de formas diferentes às ações que lhes são impressas, que possuem mecanismos que consomem energia etc." (1998a, p. 186). No entanto, o termo energia será realmente explicitado em referência à ecologia, quando é apresentada a importância de se trabalhar com a ideia de cuidar do meio ambiente a partir de ações que incluem a conservação dos espaços, a coleta de lixo e a economia de energia e água (BRASIL, 1998a).

Nesse momento, a energia (algo imaterial) é materializada e comparada à água, ou seja, a algo finito, afastando-se, completamente, de sua característica básica - a conservação. Tal processo de materialização será cada vez mais adotado, principalmente nos conteúdos de conservação ambiental nos anos iniciais do Ensino Fundamental. Ainda que identifiquemos nos Parâmetros Curriculares Nacionais de Ciências (BRASIL, 1998b) nesse nível escolar algumas orientações para se trabalhar a questão da transformação de energia, não há menção à conservação, mas uma noção que traz em si a ideia de infinitude.

O conceito de conservação será abordado de forma mais explícita no ensino médio, principalmente em Mecânica, quando se enuncia o princípio de conservação via transformação de energia potencial em cinética ou vice-versa. Nesse momento, o princípio de conservação é representado por um algoritmo, uma equação de igualdade: de um lado situa-se a energia potencial, do outro, a energia cinética. Há, ainda em Mecânica, questões relacionadas à transformação da energia total de um sistema em energia mecânica (cinética + potencial) e energia dissipada na forma de calor. Sendo representado, também, por um algoritmo, onde de um lado tem-se a energia total e do outro lado do sinal de igualdade, a energia mecânica é dissipada pelo sistema. Qualquer que seja o desenvolvimento do conteúdo, a ideia de conservação é pouco ou nada explorada, pois o maior objetivo desse algoritmo recai sobre o cálculo de uma das variáveis envolvidas. O aluno do ensino médio entrará em contato com a ideia de conservação de energia, após passar pelo conteúdo acima exposto, somente na termodinâmica, a partir do enunciado formal da Primeira Lei da Termodinâmica - o Principio da Conservação de Energia. 
A ENERGIA QUE EMERGE DAS PEÇAS PUBLICITÁRIAS

Por que propagandas? Temos como pressuposto a dinâmica do veículo publicitário na sociedade como elemento que se pretende regulador e formador de representações e formas culturais. Considerando o espaço social das mídias, podemos entender as peças de propaganda em sua relação com a formação identitária.

[...] No discurso publicitário, afluem, assim, algumas das figuras pregnantes dos imaginários socioculturais. [...] A publicidade age, então, incessantemente, para instaurar identidades, destacando, dos materiais semióticos, traços relevantes, diferenciando dentro do social, por meio de um processo de realização de discurso, figuras e espaços significantes. (SOULAGES, 1996, p. 142).

Em suas pesquisas sobre a constituição identitária via mídia, Soulages (1996) trafega pelas propagandas percebendo-as como produto cultural constituído e constituidor. Assim pensamos a publicidade como um discurso social, e entendemos as formas de representação que esse discurso faz circular como elemento constitutivo de uma bagagem cultural que o aluno leva para a escola e carrega durante seu aprendizado. Nessa dinâmica, consideramos a relação entre contexto de produção (da imagem) e o discurso imagético como constituinte do trabalho de representação. Consideramos, também, que tais produtos entram em um circuito de circulação e consumo pautado em uma visão construída de público e de produto.

As peças publicitárias selecionadas, como já indicado, constituem propagandas de um determinado gênero alimentício de conhecimento bastante difundido, o achocolatado Nescau, e de uma agência nacional de energia, a Eletrobrás. No caso desta última, trata-se de um conjunto de quatro propagandas comemorativas de seus 50 anos de existência. A escolha das peças foi aleatória, pois o foco é explorar as representações de energia em propagandas de alcance nacional e tomá-las como deflagradoras de uma discussão. Selecionamos, para este artigo, duas peças de cada.

\section{NESCAU A ENERGIA QUE DÁ GOSTO}

O slogan associado ao achocolatado Nescau pode ser considerado um dos mais populares, porém seu surgimento data de 1972, cerca de 40 anos após o surgimento do alimento. Vários sites de propaganda referenciam pesquisas sobre a popularidade do Nescau e da marca que as propagandas do produto deixaram na memória do público. Finalmente, no próprio site do 
produto, há a informação de que Nescau é o achocolatado em pó que mais vende no Brasil (NESTLE, 2012). A associação com o termo energia levou a que outros produtos da linha tivessem o mesmo apelo, como no caso do Nescau cereal. As peças televisivas que encontramos, todas a partir do período do slogan de 1972, trabalham com encenações nas quais um grupo de crianças, ao tomar Nescau, experimenta um momento de aventura via imaginação. Com a palavra energia associada ao produto, a aventura apresenta outros contornos, sempre associando Nescau aos jovens e aos esportes radicais.

PeÇA 01

Três jovens (dois meninos e uma menina) se divertem tomando Nescau e brincando com um trem que se move por um grande circuito montado com vários obstáculos. Uma árvore de brinquedo cai no trilho e a encenação muda. A menina passa a estar vestida como uma dama do século XIX em um vagão de trem (em uma clara referência aos filmes de western), e o rapaz se esforça para retirar, com suas próprias mãos, uma árvore que caiu nos trilhos e impedir que o trem com a "mocinha" descarrilhe. Como narra uma voz que fala com o expectador durante a cena, Nescau tem mais vitamina, força e energia... Com isso, fica difícil o rapaz não retirar a árvore e salvar a garota. Essa propaganda, com cerca de 30 segundos, é referenciada como sendo dos anos de 1970. Pelo uso do slogan ela é, no mínimo, posterior à 1972.

PEÇA 02

Três garotos tomam Nescau na cozinha e da torneira sai "uma serpente monstruosa feita de água" para atacá-los. Um deles pega a lata de Nescau e joga contra a torneira que se fecha fazendo o monstro desaparecer. Essa propaganda é mais curta, cerca de 15 segundos. A data é indicada como sendo dos anos de 1990.

\section{ELETROBRÁS E A ENERGIA COMO O NEGÓCIO DO FUTURO}

Como já afirmado, as peças escolhidas fazem parte de uma campanha de comemoração dos 50 anos da Eletrobrás. Elas contam histórias que envolvem a empresa e sua trajetória associada ao desenvolvimento do país. Tanto falam do que já foi feito quanto o que se pensa para o futuro, em uma 
estratégia que podemos denominar de afirmação e projeção. A energia, no contexto dessas peças publicitárias, surge como produto.

PEÇA 01

A narrativa em over começa mostrando um funcionário da Eletrobrás que tem orgulho de participar de uma história de sucesso: levar energia para um país inteiro. A abertura apresenta uma chamada: Reinventando a energia, por José Leonardo. Esse é o nome do funcionário que participa, segundo a narração, de um sistema único no mundo. As imagens vão mostrando José Leonardo chegando ao trabalho e instruindo outros trabalhadores (é quando o narrador informa que "é com a sua força que a Eletrobrás movimenta a nação de ponta a ponta"); passa por homens trabalhando nas linhas de transmissão, imagens de grandes centros urbanos iluminados e fábricas automatizadas funcionando. A narração em over informa: em breve, José Leonardo irá levar essa experiência a outras nações; então, ele não estará transmitindo somente energia, mas também conhecimento. A peça vai chegando ao fim mostrando o rosto feliz de José Leonardo e a voz over informando:"Eletrobrás. Há 50 anos a nossa energia transforma a vida dos brasileiros". O slogan ao final: Eletrobrás, energia para os novos tempos.

PEÇA 02

Com a mesma chamada - Reinventando a Energia: Romeriton Miranda - a história começa na fazenda de Romeriton, com ele ido ordenhar, mecanicamente, as vacas. A voz over informa que a Eletrobrás investe sempre para que a energia chegue a todo cantinho do Brasil. As imagens mostram o gado de Romeriton, sua família e sua propriedade, com a narrativa informando que ao chegar a qualquer canto do Brasil, a Eletrobrás não leva, somente, energia, mas leva, também, cidadania, pois já são mais de 14 bilhões de beneficiados que usam a luz para aumentar a produção e a renda. $O$ mesmo final, com um close em Romeriton: “Eletrobrás. Há 50 anos a nossa energia transforma a vida dos brasileiros". Eletrobrás, energia para os novos tempos.

\section{A ENERGIA COMO FOCO}

No trabalho analítico, consideramos a relação entre um público construído com fins midiáticos de venda de uma mercadoria e o modo de construção do texto. Com relação ao público, Soulages afirma que a quem 
falar e como falar são questões difíceis no contexto da cultura de massa. A construção do público tem como base, contemporaneamente, alguns fatores como o capital cultural, proximidade, alcance da peça publicitária, etc. Assim, "quanto mais o 'alvo' é próximo e conhecido, mais a mensagem se apresenta de maneira explícita e unívoca" (p. 149), e se os receptores são 'mais distantes', anônimos, como no caso da comunicação de massa, aquele que comunica deve se esforçar em "[...] forjar um elo simbólico, mas sempre hipotético, com os sujeitos interpretantes, recorrendo a saberes, normas, valores e universo de referência supostamente partilhado" (SOULAGES, 1996, p.150). A estratégia das mensagens publicitárias consiste em colocar em cena universos significantes abertos em relação aos sujeitos-alvo, de modo que haja uma identificação-projeção. Nesse processo, o sujeito comunicante (que em nossas análises podemos identificar como as empresas Nestlé e Eletrobrás) procura "falar de outras coisas além do produto e pôr em cena uma série de representações do mundo e de seus seres" (p. 150).

Comecemos com o caso das propagandas de Nescau. Em todas elas, as personagens são jovens envolvidos em situações de ação e aventura, que apelam à subjetividade da faixa etária que pretende atingir. Tais situações demandam força e inteligência para chegarem a bom termo: os jovens que tomam Nescau têm essas qualidades para cumprirem as tarefas exigidas em cada encenação veiculada. Na primeira peça analisada, temos as imagens do garoto levantando um tronco de árvore (à semelhança de um super-herói) que caiu sobre os trilhos do trem, enquanto a voz over fala sobre Nescau: Mais vitaminas... Mais força e energia... A associação entre energia+força é evidente pela conjunção entre imagens e narração, deixando energia como equivalente a trabalho. Isso nos permite evidenciar, no presente caso, que a força é uma qualidade adquirida quando os jovens ingerem Nescau. A segunda peça analisada não apresenta nenhuma narração, apoiando-se completamente nas imagens para mostrar o slogan clássico, ao final: Nescau, energia que dá gosto. Tal conjunção traz, novamente, a associação da energia à força (o rapaz vence a "serpente" que sai da torneira) e à agilidade física e mental. A rapidez na ação permite que eles não sejam atacados.

O que as propagandas constroem é uma associação relativamente simples: alimento gera energia e essa energia deixa mais forte e inteligente. A ideia de transformação está subsumida no processo que leva da ingestão de Nescau à realização de atividades físicas e intelectuais. No entanto, essa noção parece se distanciar de como o conceito é trabalhado no campo da física. Aqui, nas peças, a transformação, como elemento relacionado ao conceito energia, 
distancia-se do que poderíamos denominar repertório de conhecimento escolar para aproximar-se do cotidiano, sem maiores complexidades.

No caso das propagandas da Eletrobrás, alguns elementos são mais elaborados. Inicialmente, o público-alvo é todo cidadão brasileiro para quem a Eletrobrás deseja construir uma imagem. A energia surge de suas peças publicitárias como um produto de seu trabalho, como sua matéria-prima. As duas foram escolhidas considerando as personagens e sua ambientação: José Leonardo é um funcionário da empresa e Romeriton, um pequeno proprietário e fazendeiro que se beneficia da energia. Cada personagem é construída para dar conta de uma diversidade presente no país. Elas são sínteses de grupos e para eles é que a Eletrobrás fala. E como ela fala de energia?

Com José Leonardo (peça publicitária 01), a chamada inicial é "Reinventando a Energia", e temos cenas em que ele está trabalhando em torres de transmissão e outros cenários relacionados à eletricidade. A voz over começa afirmando que "Levar energia a um país inteiro é um desafio". A partir desse mote, a propaganda vai construindo tanto o orgulho do funcionário quanto o orgulho da empresa. A palavra energia aparece em evidente associação com a ação de transmitir e transformar; ela é agente dos verbos. Isso é evidenciado na narrativa e nas cenas que mostram os funcionários trabalhando em torres de transmissão, reforçando a imagem, de modo sub-reptício, da força e do trabalho. A campanha, cuja personagem é Romeriton (peça publicitária 02), tem como chamada "Reinventando a Sustentabilidade"e começa com imagens da fazenda de Romeriton, passando a imagens das torres de transmissão por vastos territórios. Depois passa à família de Romeriton em seu cotidiano, trabalhando, fazendo refeições, com uma narração informando que a Eletrobrás não leva só energia, leva, também cidadania. A ideia latente nessa campanha é a de que com a energia elétrica há aumento da produção, da renda e melhoria de vida. Como anuncia ao final: "Não há energia mais poderosa do que essa". A campanha tanto alarga quanto restringe o sentido de energia. Se nesse momento energia é associada à eletricidade, em contrapartida, ela torna-se sinônimo de desenvolvimento socioeconômico, motor de um crescimento pleno que leva à cidadania. Afinada com a perspectiva da Revolução Técnica e Científica, nessa peça de campanha da Eletrobrás, a energia é equivalente aos efeitos provocados pela eletricidade no uso do maquinário necessário ao trabalho. Nessa linha de argumentação, temos, agora, a energia associada à força (trabalho) e ao fator econômico, e essa cadeia está no cerne da sustentabilidade, pois essa peça de campanha centra-se nesse conceito. 
Nas duas peças da Eletrobrás, as personagens aparecem em ambientes próprios à sua caracterização: local de trabalho orientando equipes (José Leonardo); na fazenda trabalhando e no cotidiano com a família (Romeriton). Nelas a energia transmuta-se em eletricidade por meio de uma argumentação que deixa, naquele que vê as propagandas, a certeza de que nossa vida contemporânea não seria possível sem esse elemento. A força e o trabalho estão presentes nas ações das personagens que, por conta da possibilidade que a eletricidade oferece, conseguem realizar suas atividades sociais e econômicas. A argumentação colocada em ação nessas peças traz a energia como uma invenção, um elemento que é produzido, unicamente, pelo homem, materializando-a em um processo que elimina sua natureza de infinitude, além de não considerar o estado de energia de outros sistemas existentes na natureza. Dessa forma, a energia apresentada por essa propaganda não encontra paralelo no modo como tal conceito é trabalhado no campo da física.

MAS AFINAL, O QUE É ENERGIA?

Aqui as respostas vêm de dois campos. A partir da Física e das propagandas. Rediscutir no espaço da educação formal algumas noções fundamentadas no senso comum é uma das tarefas no ensino de ciências. Por isso, deparamo-nos com diferentes entendimentos sobre o que é energia, e que contradizem, em determinados termos, uma proposta largamente debatida, no campo da educação cientííca, de tornar o cidadão um conhecedor das informações científicas, dos conceitos e até mesmo dos processos que envolvem o fazer científico. Nesse sentido, temos, em torno de um conceito fundamental da área de Física, uma complexa rede de sentidos que forma uma imagem de energia distanciada daquela que deveria sustentar o conhecimento sobre como ela é vista na área. Retomando a afirmação de Soulages (1996) sobre como em algumas circunstâncias às propagandas colocam, para além do produto, elementos do universo cultural significativo a fim do público, vemos a construção em um movimento duplo: nas propagandas de Nescau (que é o produto), o além do produto é a energia; naquelas da Eletrobrás (cujo produto é a energia), o além do produto é um conjunto de qualidades que dão o tom da vida contemporânea: cidadania, sustentabilidade e progresso. Como tal associação remaneja entendimentos sobre energia é uma especulação que colocamos a partir dos estudos dos produtos culturais midiáticos. 
Vimos como o conceito de energia, em Física, tem atrelado a si um elemento que lhe é constitutivo: a conservação. Assim, os conteúdos que dão conta desse conceito, devem centrar-se na discussão sobre o aspecto da conservação que dá à energia uma dinâmica nos sistemas. Talvez a complexidade resida na íntima relação entre energia e força, presente desde a formulação da Lei de Conservação de Energia. No entanto, se em termos de ciência, essa relação deve ser problematizada, considerando o papel de cada uma dessas noções em um sistema teórico, as propagandas, como produtos da cultura de massa, sintetizam tal complexidade e fazem com que, no cotidiano, energia seja, efetivamente, força e eletricidade. Os verbos de ação que acompanham o termo energia em todas as propagandas dão conta desse aspecto. Para os jovens no espaço do aprendizado formal, energia fornece algo para termos força; ela transforma a vida das pessoas porque ela é a eletricidade que chega às casas e à indústria; ela é transmitida via cabos e torres de transmissão. Ela modifica uma situação inicial, pois o jovem que toma Nescau torna-se mais forte e os cidadãos comuns da campanha da Eletrobrás veem a energia (elétrica) em ação no progresso do país.

O jovem que tem contato com o conteúdo de física deve coordenar a perspectiva de uma energia como conceito que define algo não material (ou seja, uma abstração que está presente em sistema e tem como propriedade fundamental a conservação) com uma energia que se materializa no cotidiano cultural e tem um lugar fixo - o poste de luz - e uma ação pontual - dar força para realizar ações. Assim, entendemos que essas representações de energia, construídas conforme o objetivo propagandístico, ao circularem na mídia constituem o que Jedlowski (2005) denomina memória comum, ou seja, um conjunto de memórias que os sujeitos comuns compartilham por estarem expostos às mesmas mensagens midiáticas. No caso, as peças de propaganda de Nescau constroem uma associação de energia com a ingestão alimentar que resulta em força e inteligência. No caso da Eletrobrás, há uma construção mais elaborada que atrela energia a conceitos mais relacionados ao social e cuja complexidade no campo teórico é evidente, mas que circulam no nosso cotidiano: sustentabilidade, desenvolvimento econômico, informação. A circulação e consolidação dessas ideias-imagens são garantidas pelo número de peças propagadas e pela vinculação que tais mensagens estabelecem entre o repertório que o sujeito comum possui sobre as formas de energia e a energia que elas querem deixar como marca/produto. A memória comum vai se construindo a partir dessas representações, tendo em vista, também, que há um volume de informações oriundas do campo 
científico que se transforma durante esse processo. Nesse ponto, podemos encaminhar algumas sugestões de respostas às nossas inquietações iniciais. Há justaposições entre os significados de energia que circulam em comerciais de determinados produtos e a conceituação científica? Se entendermos que tais justaposições originam significações outras que se distanciam do conteúdo científico escolar, vemos que a possibilidade é concreta, mas tal transformação oriunda da justaposição é complexa. Considerando as questões mais contemporâneas colocadas pelas teorias de recepção, a passividade do sujeito receptor não é mais um elemento presente. Pelo contrário, tal sujeito é percebido como produtor de significados que escapam a uma possível determinação ou objetividade da mensagem e a um desejado controle da polissemia. Assim, o que colocamos como justaposição deve considerar esse ponto no qual se encontram a representação que circula e se consolida pelas peças de propaganda, constituindo essa memória comum, e os demais significados atribuídos à energia que constituem o repertório do sujeito, abarcando, inclusive, os conteúdos científicos. As qualidades associadas à energia, em tais publicidades, não acarretariam distorções na própria forma de significar energia a partir dos conteúdos de física? Intrinsecamente associada à primeira pergunta, aqui podemos pensar na consolidação de uma imagem de energia estreitamente ligada a um aspecto material, concreto. Ela circula e se torna um produto negociável, consumível; necessita de um suporte para sua existência (como os fios condutores de energia elétrica). Antes de chegar a discutir o conteúdo conceitual, o sujeito já passou por essas e outras tantas representações de energia que conjugam qualidades e ações: energia limpa; energia que leva ao progresso; energia que dá força; etc. O modo abstrato de pensar o conceito no campo científico defronta-se com perspectivas que se apoiam em associações mais cotidianas, como força, consumo e desenvolvimento, exigindo um movimento de construção de conhecimento que agrega à energia outros tantos conceitos abstratos, como conservação e transformação que se contrapõem aos conceitos cotidianos. 
REPRESENTATIONS OF ENERGY CIRCULATING INTHE MEDIA AND THEIR NATURE IN THE CONTEXT OF SCIENCE EDUCATION

ABSTRACT: In this study we discuss different modes of signification of the word energy in the discourses of different spaces in which the subjects circulate by comparing to its production context in physics. We focus on the use of the term energy in certain advertisements widely circulated in the media. From our arguments we understand that when the representations of energy, constructed according to the purpose of advertisements, circulate in the media, they constitute a set of memories that common subjects share through being exposed to the same media messages. The abstract way of thinking about the concept in science is confronted with perspectives based on everyday associations, requiring a movement of knowledge construction that gives energy many other abstract concepts.

KEYWORDS: Teaching science. Meanings of energy. Media devices. Discourses.

REPRESENTACIONES DE ENERGÍA QUE CIRCULAN EN LOS MEDIOSY SU NATURALEZA EN EL CONTEXTO DE LA EDUCACIÓN EN CIENCIAS

RESUMEN: Discutimos, en este artículo, los diferentes modos de significación de la palabra energía, que se encuentran presentes en las discusividades de los diferentes espacios de circulación de los sujetos, en comparación con el contexto de su producción en la física. Nos centramos en el uso del término energía en algunos anuncios publicitarios de gran circulación en los medios. Partiendo de nuestras argumentaciones, compreendemos que las representaciones de la energía, construídas de acuerdo al propósito de la propaganda, cuando circulan en los medios de comunicación conforman un conjunto de memorias que los sujetos comunes comparten, por encontrarse expuestos a los mismos mensajes mediáticos. La forma abstracta de pensar el concepto en el campo científico se enfrenta a perspectivas que se sustentan en asociaciones cotidianas, lo que requiere un movimiento de construcción del conocimiento que añade a la energía muchos otros conceptos abstractos.

Palabras Claves: Enseñanza de las Ciencias. Energía. Dispositivos mediáticos. Discursos.

\section{NOTAS}

1) Os nomes dos projetos serão inseridos posteriormente.

2) A Termodinâmica é uma área da Física que estuda os sistemas (como, por exemplo, uma bola de gás, um motor a gasolina de carro, as locomotivas a diesel) que são bem 
caracterizados por condições físicas como temperatura, pressão, volume e energia interna em momentos distintos denominados inicial e final e que constituem o que é chamado de uma função de estado.

3) Ver nota 2.

4) Isso constitui a dualidade onda-partícula. No caso da radiação solar, por exemplo, ela pode ser tratada como uma onda que se propaga (o termo radiação solar é comumente tratado como luz), ou como pacotes de energia, denominados quantuns, que formam a base da Mecânica Quântica.

\section{REFERÊNCIAS}

AUTH, M. A.; ANGOTTI, J. A. P. O processo de ensino aprendizagem com aporte do desenvolvimento histórico de universais: a temática das combustões. In: PIETROCOLA, M. (org). Ensino de Física: conteúdo, metodologia e epistemologia numa concepção integradora. Florianópolis: Editora da UFSC, 2001.

BAUMAN, Z. OMal-estar da Pós-modernidade. Revisão técnica de Luis Carlos Fridman. Rio de Janeiro: Zahar, 1998.

BELLONI, M. L.; GOMES, N. G. Infância, mídias e aprendizagem: autodidaxia e colaboração. Educação e Sociedade, Campinas, v. 29, n.104 - Especial, p. 717-746, out. 2008. BEVORT, E.; BELLONI, M. L. Mídia-educação: conceitos, história e perspectivas. Educação e Sociedade, Campinas, v. 30, n. 109, p. 1081-1102, set./dez. 2009.

BRASIL. Ministério da Educação e do Desporto. Secretaria de Educação Fundamental. Referencial Curricular Nacional para a Educação Infantil. Brasília: MEC/SEF, 1998a.

BRASIL. Ministério da Educação e do Desporto. Secretaria de Educação Fundamental. Parâmetros Curriculares Nacionais. Brasília: MEC/SEF, 1998b.

BUCUCCl, A. A. Textos de Apoio ao Professor de Física: Introdução ao Conceito de Energia. Programa de Pós-Graduação em Ensino de Física, UFRGS, v. 17, n. 3, 2006.

CLAVAL, P. A Geografia Cultural. Florianópolis: Editora da UFSC, 1999.

CUCHE, D. A Noção de Cultura nas Ciências Sociais. 2. ed. Bauru: EDUSC, 2002.

DUARTE, R. M.; ALEGRIA, J. Formação estética audiovisual: um outro olhar para o cinema a partir da educação. Educação e Realidade, v. 33, n. 1, p. 59-79, jan./jun. 2008.

DUARTE, R. M.; LEITE, C. R.; MIGLIORA, R. Crianças e televisão: o que elas pensam sobre o que aprendem com a tevê. Revista Brasileira de Educação, v. 11, n. 33, p. 497-564, set./dez. 2006.

FEATHERSTONE, M. Cultura de Consumo e Pós-modernismo. São Paulo: Estudio Nobel, 1995. 
FISCHER, R. M. B. Mitologias em torno da novidade tecnológica em educação. Educação e Sociedade, v. 33, n. 121, p.1037-1052, out./dez. 2012.

FISCHER, R. M. B. Cinema e pedagogia: uma experiência de formação ético-estética. Revista Percursos, Florianópolis, v. 12, n. 1, p. 139-152, jan./jun. 2011.

FRENCH, A. P. Mecánica Newtoniana. Barcelona: Editorial Reverté, 1974.

LARAIA, R. B. Cultura: um conceito antropológico. Rio de Janeiro: Jorge Zahar Editor, 1996.

NESTLÉ. Nescau. Disponível em: <http://www.nestle.com.br/site/marcas/Nescau. aspx.>. Acesso em: 01/03/2014.

JEDLOWSKI, P. Memória e mídia: uma perspectiva sociológica. In: SÁ, Celso Pereira de. Memória, Imaginário e Representações Sociais. Rio de Janeiro: Museu da República, 2005.

PEREIRA, R. M. R. Infância e publicidade: uma pesquisa-intervenção no contexto escolar. Cadernos de Educação, Pelotas, v. 34, p. 265-288, set./dez. 2009.

Entre o (en)canto e o silêncio das sereias: sobre o (não)lugar da criança na cibercultura. Childhood \& Philosphy, Rio de Janeiro, v. 9, n. 18, p.319-343, jul./dez. 2013. SOULAGES, J-C. Discurso e imagens publicitárias. In: CARNEIRO, A. D. et al. O Discurso da Mídia. Rio de Janeiro: Oficina do Autor, 1996.

WILLIAN, R. Palavras-chave: um vocabulário de cultura e sociedade. São Paulo: Boitempo, 2007.

VALADARES, J. A importância epistemológica e educacional do Vê do conhecimento. Actas do III Encontro Internacional sobre Aprendizagem Significativa. Lisboa: Universidade Aberta, 2000.

Carmen Irene Correia de Oliveira é graduada em Letras (Português-Francês) pela Universidade Federal do Rio de Janeiro, mestre em Memória Social e Documento pela mesma Universidade e Doutora em Ciência da Informação pela Universidade Federal Fluminense. Atualmente é Professora Adjunta do Departamento de Ciências Sociais da Universidade Federal do Estado do Rio de Janeiro - UNRIO, sendo Docente do Programa de Pós-Graduação em Educação (UNIRIO). Desenvolve pesquisas no âmbito da educação, nas temáticas de educação/cultura/divulgação científica; educação científica e imagens fixas e em movimento; memória e imagem, com discussões ancoradas nas relações entre ciência, tecnologia e sociedade.

E-mail: irenecor2004@gmail.com 
Maria Auxilladora Delgado Machado é graduada em Física pela Universidade do Estado do Rio de Janeiro (1984), mestre em Astronomia pelo Observatório Nacional (1988) e doutora em Astronomia pelo Observatório Nacional (1998). Atualmente é professora do Programa de Pós-Graduação em Educação, na Universidade Federal do Estado do Rio de Janeiro (UNIRIO) e professora adjunta do Departamento de Ciências da mesma universidade onde desenvolve pesquisa em formação inicial e continuada de professores de ciências a partir de parcerias com escolas públicas de ensino fundamental e médio. Trabalha também com a relação ciência e artes na dinâmica de ensino-aprendizagem de ciências.

E-mail: dora.dm@smail.com

GuaraciRa GouvêA de Sousa é graduada em Física pela Universidade de São Paulo (licenciatura) e pela Universidade Federal do Rio de Janeiro (bacharelado), mestre em Filosofia da Educação pela Fundação Getúlio Vargas e doutora em Educação, Gestão e Difusão em Biociências pela Universidade Federal do Rio de Janeiro. Atualmente, é Professora Associada I da Universidade Federal do Estado do Rio de Janeiro - UNIRIO, docente permanente do Programa de Pós-Graduação em Educação desta instituição; pesquisadora credenciada/docente colaboradora no Programa de Pós-Graduação em Educação em Ciências e Saúde da Universidade Federal do Rio de Janeiro. Tem experiência na área de Educação, com ênfase em educação não formal, mídias e educação à distância, atuando principalmente nos seguintes temas: educação em ciências, linguagens/imagens, museu de ciências e formação de professores presencial e à distância.

E-mail: suaraciras@uol.com.br 